\author{
Mohammed A. Fayad \\ Energy and Renewable \\ Energies Technology Center, \\ University of Technology, \\ raq, Baghdad \\ 11013@uotecnology.edu.iq
}

\section{Bashar R. AL-Ogaidi}

Energy and Renewable Energies Technology Center, University of Technology, Iraq, Baghdad

130110@uotechnology.edu.iq

Received on: 12/01/2019

Accepted on: 30/05/2019

Published online: 25/10/2019

\title{
Investigation the Morphological Characteristics of the Particulate Matter Emissions from the Oxygenated Fuels Combustion in Diesel Engines
}

\begin{abstract}
Understanding the size and morphological properties of particulate matter (PM) is essential to improve analysis of the process of PM formation in diesel engines. These will help to reduce undesirable environmental impact and health effects. A scanning mobility particle sizer (SMPS) and thermal gravimetric analysis (TGA) were used to study the changes in size characteristics of PM/soot and soot reactivity. Furthermore, improve the oxidation of soot particles in diesel engines is necessary under the range of different fuel combustions. Oxygenated fuels (e.g., ethanol blend, E10 and butanol blend, B16) were used in this experimental study to show how insignificant changes in morphological characteristics and activity of PM.

The oxidation and activation energy of PM was achieved at the lower temperature from the combustion of oxygenated fuels compared with diesel fuel combustion. Besides, it was found that both the size of soot particulate and the number of primary particles are reduced with increasing the oxygen content in oxygenated fuels than the diesel fuel. The shape of primary soot particle for PM is a bit more spherical in the case of diesel fuel than to the oxygenated fuels.

Keywords- Particulate matter, PM oxidation, Oxygenated fuel, Combustion, Soot particles, Diesel engine, TGA.
\end{abstract}

How to cite this article: M.A. Fayad, and B.R. AL-Ogaidi, "Investigation the Morphological Characteristics of the Particulate Matter Emissions from the Oxygenated Fuels Combustion in Diesel Engines," Engineering and Technology Journal, Vol. 37, Part A, No. 10, pp. 384-390, 2019.

\section{Introduction}

Some of the particulates in the air are of inorganic composition, hence are stable and cannot be reduced [1]. In recent years, the researchers have been deeply focused on reducing/control the particulate matter (PM) due to the significant concerns on public health, which can lead to respiratory cardiovascular diseases [2]. The improvement in engine combustion temperature and reduction of PM remains still need more search and analysis $[3,4]$. It is reported that the temperature and residence time for soot oxidation can be changing the morphological characteristics of soot particulates $[5,6]$. The size and structure of PM have received attention in recent years because of its implication for diesel after treatment systems, especially in Diesel Particulate Filters (DPF) [7]. Most of the studies have been conducted on only diesel fuel and analysis of the number and amount of the produced PM [8]. In general, the internal analysis structure of soot particle is indispensable during the soot particle oxidation and formation to estimate the methods of PM reduction $[9,10]$.

Two suggested strategies (fuel composition and engine operating conditions) have a high potential effect of increasing diesel soot reactivity and structure. It is reported that the physicochemical properties have a vital role in soot reactivity [11] In previous experimental work, it is documented that the soot particles from biodiesel fuel combustion are more reactive than those emitted from the combustion of conventional fuel $[6,12]$. For example, the rate of soot particle oxidation increases from biodiesel fuel combustion. Therefore, the lower temperature is required for regeneration of the DPF [12]. The soot oxidation behavior from the diesel fuel combustion was studied by Fang and Lance [7]. They concluded that the increases time of DPF regeneration leads to reduce the soot reactivity.

On the other hand, the soot generated from high engine load is oxidized slower than soot generated from low engine load for the same fuel $[13,14]$. Consequently, it is confirmed that the combustion conditions have a direct effect on the reactivity of diesel soot particles under which the PM was formed. It is reported that the activation energies are 110 and $162 \mathrm{~kJ} / \mathrm{mol}$ for both diesel soot and flame soot, respectively [15]. Yezerets et al. [16] reported that the soot particulate produced from diesel fuel combustion for different engines are not the same soot morphology and reactivity between samples. The structural characteristics of diesel soot primary particles were investigated and evaluated during the oxidation process by 
Ishiguro et al. [17]. The unique oxidation mechanism of soot particulate generated from biodiesel was identified in experimental work by Song et al. [12].

Oxygenated fuels (butanol and ethanol) are attractive alternative fuels for use in diesel engines. In recent years, oxygenated fuels have become a good alternative to diesel fuel due to meet the stringent emission regulations. There are some obstacles $[3,18]$ to use alcohol fuel in diesel engines such as low cetane number, high latent heat of vaporization, and lower calorific value. In contrast, it is reported that butanol has good lubricity properties when blended with biodiesel. In comparison between alcohol fuels, butanol has good chemical and physical properties than ethanol such as higher energy density, better solubility in diesel fuel, less prone to water contamination and higher cetane number compared to the ethanol. Therefore, alcohol fuels mixed with diesel fuel or biodiesel in different percentage to improve the cetane number and to extend use in compression ignition (CI) diesel engines $[19,20]$. Moreover, it is stated that the butanol blended with diesel fuel in percentages from $10-20 \%$ by volume without any modification in diesel engines. Several experimental works documented that the oxygenated fuels lead to increase the fuel consumption and increases the thermal brake efficiency. It is reported that the energy crisis and environmental degradation can be addressed by using oxygenated fuels. Also, the carbon monoxide and soot particulate are significantly reduced when addition butanol to the pure diesel fuel [21-23] with a high decrease in PM emissions due to the oxygen content in the fuel molecules $[24,25]$. In recent studies by Fayad et al. [3] and Zhang et al. [26] presented that oxygenated fuels increased the soot oxidation and reduced the soot particulate formation during the combustion cycle, hence change the shape and size of soot agglomerates. The present work aims to investigat the factors affecting the morphological characteristics of $\mathrm{PM} /$ soot and activation energy of soot particles from the oxygenated fuels. Furthermore, analysis of the activation energy (reactivity) of PM from the combustion of oxygenated fuels and comparing with diesel fuel.

\section{Experimental setup}

\section{Research Engine Specification}

The single-cylinder direct fuel injection diesel engine was used in this experimental work, equipped with instruments to measure both engine load and speed. The schematic diagram of the experimental setup and equipment is shown in Figure 1. The engine specifications used in this study and details are illustrated in Fayad et al. [27] and Sukjet et al. [18]. The soot generated from this engine under $1500 \mathrm{rpm}$ and load with 3bar Indicated Mean Effective Pressure (IMEP). The samples of PM/soot from different fuels were collected from the exhaust duct of the engine. The quartz filters were used to collect the highvolume of gram-sized samples of diesel soot. The diameter of the quartz filter is $47 \mathrm{~mm}$ and taken 45 min to collect the sample of PM. The engine was run at constant engine speed of $1500 \mathrm{rpm}$, 180 bar of injection pressure, and 4 bar of IMEP for all engine tests.

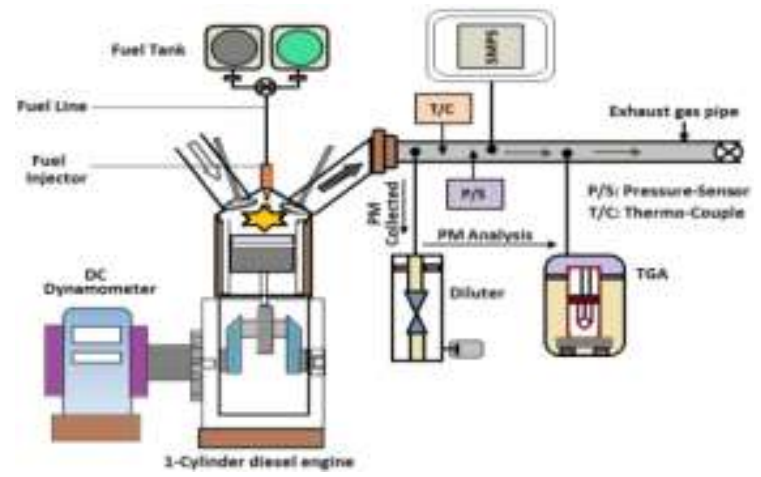

Figure 1: Schematic diagram of single cylinder diesel engine

\section{Fuels and Fuel blends}

The diesel fuel and alcohol fuels (butanol and ethanol) were used in this experimental study to understand the effect of different fuels on soot particle reactivity and structure. The diesel fuel was mixed with butanol, ethanol, and biodiesel to produced fuel blends. Besides, the biodiesel was used in the mixture to avoid the problem of phase separation in fuel blends and enhance fuel properties [18]. The fuel blends are freshly prepared before the experimental test. The basic properties of diesel fuels and blended fuels are presented in Table 1. The proportion of butanol and ethanol to the fuel blend was $16 \%$ and $10 \%$ by volume respectively to produce the same value of oxygen content in the fuel blends. The total percentage of fuel blends are summarized below: Butanol blend (B16R15D): 69\% Diesel fuel + $15 \%$ RME + 16\% Butanol

Ethanol blend (E10R15D): 75\% Diesel fuel+ $15 \%$ RME $+10 \%$ Ethanol. 
Table 1. Characteristics of the test fuels $[18,27]$.

\begin{tabular}{|c|c|c|c|c|c|}
\hline Propertics & Diviel & Butanal & Elasaat & 116R15D & EIER15D \\
\hline Cheniod formule & $\mathrm{C}_{1} \cdot \mathrm{H}_{ \pm 1}$ & $\mathrm{C}, \mathrm{H}, \mathrm{OH}$ & $\mathrm{C}_{3} \mathrm{H}_{3} \mathrm{OH}$ & $\mathrm{C}_{1}, \mathrm{H}_{31}+\mathrm{O}_{2}$ & $\mathrm{C}_{41} \mathrm{H}=\mathrm{O}_{24}$ \\
\hline Cetaine tamber & 539 & 17 & 8. & & 472 \\
\hline $\begin{array}{l}\text { Latedthent of } \\
\text { vaparixstion (alkg) }\end{array}$ & 24341 & 985 & 8sa & & \\
\hline buik modidus iMPD) & $1+10$ & 1500 & 1320 & & \\
\hline dennity at IS 'C (on in') & 827.1 & 8095 & 789.4 & 835.2 & 8313 \\
\hline $\begin{array}{l}\text { kintmatic vigcosity at } 46 \\
\text { "C (est) }\end{array}$ & 2,70 & 1.23 & 113 & 254 & 260 \\
\hline $\begin{array}{l}\text { tower calurific vatue } \\
(M a k g)\end{array}$ & 4) 11 & 33.12 & 2683 & W.8? & 387 \\
\hline futricity at $60^{\circ} \mathrm{C}$ Cuma & 312 & 820 & 656 & 405 & 404 \\
\hline Flat poim (C) & 50 & 29 & 14 & 32 & 19 \\
\hline$c($ ut 6$)$ & 6644 & $04 \pi$ & $\$ 214$ & 8156 & $* 1,00$ \\
\hline $\mathrm{H}(\mathrm{m}+2)$ & 1356 & $2 \mathrm{t}$ & 13.13 & 13,34 & 13.9 \\
\hline$O(w+2)$ & 0 & 21.59 & 34.73 & 508 & 500 \\
\hline$O$ thos OH Eoup (WT to6) & 0 & 21.41 & 473 & 336 & 3.01 \\
\hline Boling paint $(C)$ & 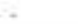 & 1175 & 75.3 & & \\
\hline
\end{tabular}

\section{Experimental equipment used}

The size and concentration of particulate matter (PM) emissions were measured along the exhaust gas duct of diesel engines by employing the high accuracy equipment of SMPS (scanning mobility particle sizer). The number, concentration, and size of PM were evaluated by using model TSI SMPS 3080-particle number and size classifier with thermodilution. Thermal Gravimetric Analysis (TGA) was used to determine the thermal stability of $\mathrm{PM} /$ soot collected from the exhaust duct. It was used to investigate the soot reactivity from the PM samples collected from the combustion of different fuels. The level of program temperature for TGA was set at $650{ }^{\circ} \mathrm{C}$ in the air atmosphere to oxides the soot and to limit the filter decomposition. The venture nozzle diluter was located at the exhaust pipe to collect the sample of PM. Glass fiber filter $(47 \mathrm{~mm}$ diameter) was used to collect PM in the exhaust duct for $45 \mathrm{~min}$ at a flow $9 \mathrm{~L} / \mathrm{min}$. The heating program in TGA is presented in Table 2.

Table 2: Thermal Gravimetric Analysis (TGA) heating program

\begin{tabular}{|l|l|l|}
\hline Step & Process & Time and termperature \\
\hline 1 & \multicolumn{2}{|l|}{ Initial atmosphere: nitrogen } \\
\cline { 2 - 3 } 2 & Isothermal & 10 min at $40^{\circ} \mathrm{C}$ \\
\cline { 2 - 3 } 3 & Heating ramp & $3^{\prime} \mathrm{C}$ min from $40^{\circ} \mathrm{C}$ to $400^{\circ} \mathrm{C}$ \\
\cline { 2 - 3 } 4 & lsothermal & for 30 min at $400^{\circ} \mathrm{C}$ \\
\cline { 2 - 3 } 5 & Cooling ramp & from $400^{\circ} \mathrm{C}$ to $100^{\circ} \mathrm{C}$ at $3^{\circ} \mathrm{C} /$ min \\
\hline 6 & Change of atmosphere to air \\
\cline { 2 - 3 } 7 & Heating ramp & from $100^{\circ} \mathrm{C}$ to $650^{\circ} \mathrm{C}$ at $3^{\circ} \mathrm{C} /$ min \\
\hline \multirow{2}{*}{8} & Isothermal 60 min at $650^{\circ} \mathrm{C}$ \\
\hline 9 & Cooling ramp & from $650^{\circ} \mathrm{C}$ to $20^{\prime} \mathrm{C}$ at $50^{\circ} \mathrm{C} /$ min \\
\hline
\end{tabular}

\section{Results and Discussion}

\section{Particle size distribution PSD}

The size distributions of particulate matter (PSD) at the exhaust pipe were obtained for different fuels to produce a variety PM along the exhaust pipe, as shown in Figure 2. It was observed that the number of particulates was considerably reduced from oxygenated fuel combustion when compared to the combustion of the reference fuel (diesel fuel). Oxygen content in fuel blends is the main reason to reduce the number of PM in the combustion chamber $[19,27]$. Besides, reduce the particle precursors and formation of soot particle as well as improving the particle oxidation supports the PM reduction. It is documented in the earlier experimental studies that the oxygenated fuels reduce the particulate number concentration inside the combustion cycle and along the exhaust duct [28]. In the case of oxygenated fuels, it can be observed that the PM produced from the butanol blend (B16) combustion was slightly lower than the ethanol blend (E10) combustion. This is due to the high cetane number and bulk modulus in B16 compared to the E10 resulting in complete combustion $[29,30]$ and thus enhancing particulate oxidation.

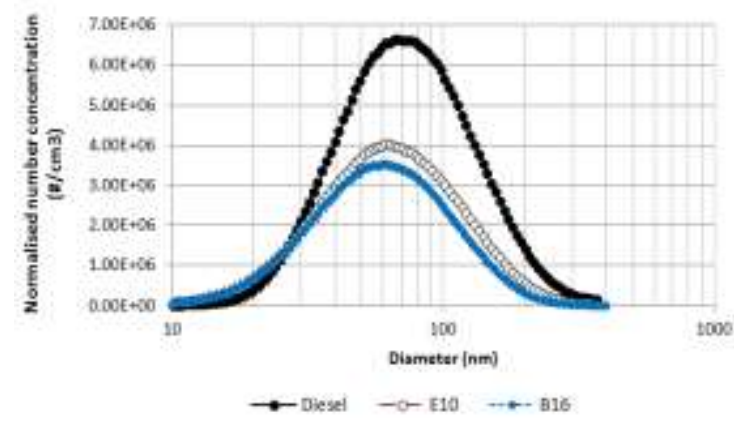

Figure 2: Particle size distribution (PSD) for diesel, E10 and B16 blends

\section{PM oxidation and activation energy}

The temperature of PM oxidation and activation energy for different fuel blends are shown in Figure 3. It can be observed that the temperature of PM oxidation for oxygenated fuels is lower than the diesel fuel. The oxygen-born can explain this in fuel [31], which can increase PM oxidation at lower temperatures. For the same oxygen content, it can be reported that the oxidation temperature of PM for B16 is lower when compared to the E10. Furthermore, it is believed the oxygen content in the hydroxyl group of B16 is more efficient in soot particulate oxidation [12,32]. In addition, the high combustion temperature of B16 enhances the PM oxidation in the combustion cycle and along the exhaust pipe then to the E10. The same trend was achieved in the case of activation energy. It can be said that oxygenated fuels have hydroxyl radical contributes to reducing the temperature required for PM oxidation as well as the lower activation energy for start soot particulate oxidation [12,33]. This can be beneficial for after treatment design 
and how they PM oxidized in lower temperature and energy over diesel oxidation catalyst (DOC) and diesel particulate filter (DPF).

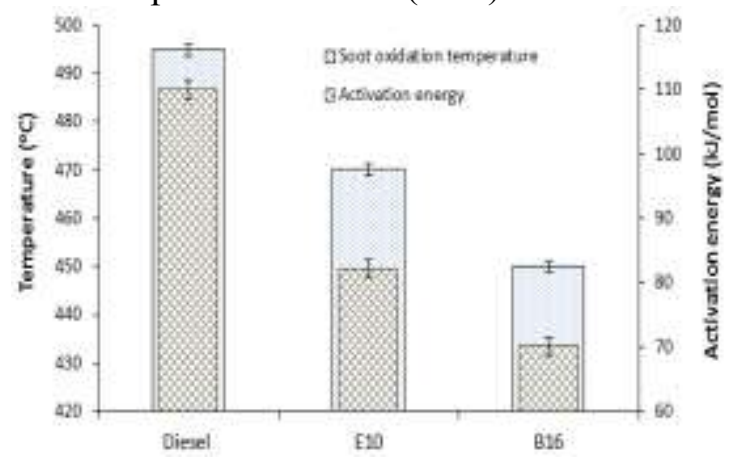

Figure 3: Activation energy and oxidation temperature of PM for diesel, E10 and B16 blends.

The oxidation of PM for different fuel blends with time, as presented in Figure 4. It noticed that the PM produced from the combustion of oxygenated fuels are more reactive than those produced from diesel fuel. This could be due to the internal structure of these particles (a disorder of graphene layer form), which leads to improving the particulate soot oxidation [23]. It can be noticed a slight difference in PM oxidation time between oxygenated fuels. For example, B16 is oxidation at a slightly lower time than E10 for the same oxygen content [34]. This could be for many reasons like the effective oxygen content in the fuel molecule and enough resident time of PM for soot oxidation.

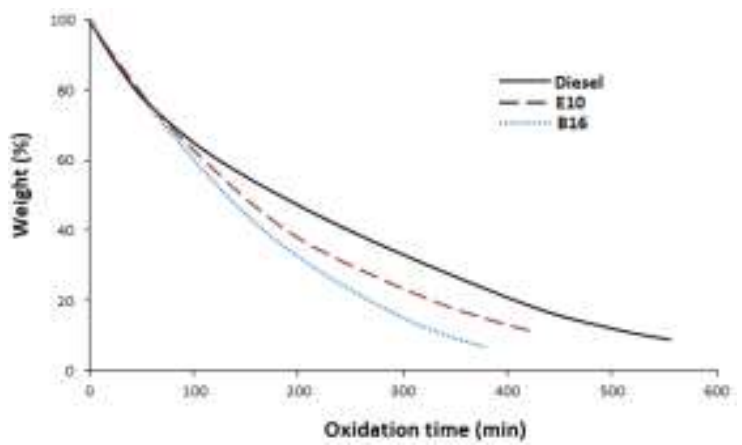

Figure 4: Particulate matter (PM) oxidation time for diesel fuel, E10 and B16 blends

\section{PM Morphology}

Figure 5 shows the physical properties of PM for oxygenated fuels and diesel fuel. The average radius of gyration and the number of primary particles are lower from the combustion of oxygenated fuel than for diesel fuel, as shown in Figures 5 and 6 , respectively. It is believed that oxygen content in E10 and B16 leads to enhance PM oxidation and reduced the formation of PM $[35,36]$ as well as oxidize the primary soot particles that already formed by disappearance the fraction of primary particles. Also, oxygenated fuels inhibited the likelihood of collisions between particles and agglomerates. As well as between soot agglomerate with resulting in lower number of primary particles $[27,37]$ and reduces the size of PM agglomerate [3,35]. It is stated that the formation rate of PM increases from diesel fuel combustion leading to produces the high number of primary particles [38]. A slight reduction in morphological parameters was noticed with B16 than to the E10 for the same amount of oxygen content, as shown in Figures 5 and 6. It justified because of the chemical structure of the B16 blend and the lack of polycyclic aromatic hydrocarbon (PAH) as well as high combustion temperature, resulting in decreases in the formation of soot precursors more than E10 blend.

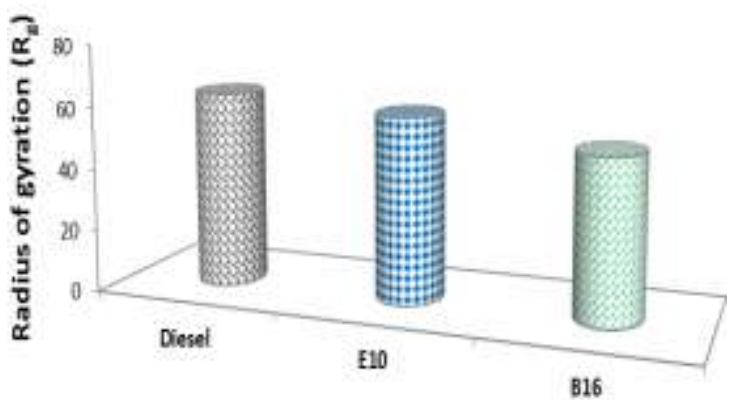

Figure 6: Effect of oxygenated fuels on radius of gyration $\left(\mathbf{R}_{\mathrm{g}}\right)$

The average diameter of primary particle (dpo) in PM for both diesel fuel and oxygenated fuels (B16 and E10) are shown in Figure 7. According to the results, it can be observed that oxygenated blends have a smaller average size of primary particles (from 21-24 nm) than diesel fuel (28 $\mathrm{nm})$. This is due to the higher oxidative reactivity, lower rate of PM precursor's production and particulate soot growth over the fuel blends combustion (oxygenated fuels) compared to the diesel fuel combustion. The general trends of dpo resulting from Figure 7 are an agreement with previous experimental works by Park et al. [36] and $\mathrm{Qu}$ et al. [39] that oxygenated fuel produces the smaller size of primary particles than conventional diesel fuel (bigger size). Furthermore, a slight difference in the size of the primary between oxygenated fuels was observed in Figure 7. 


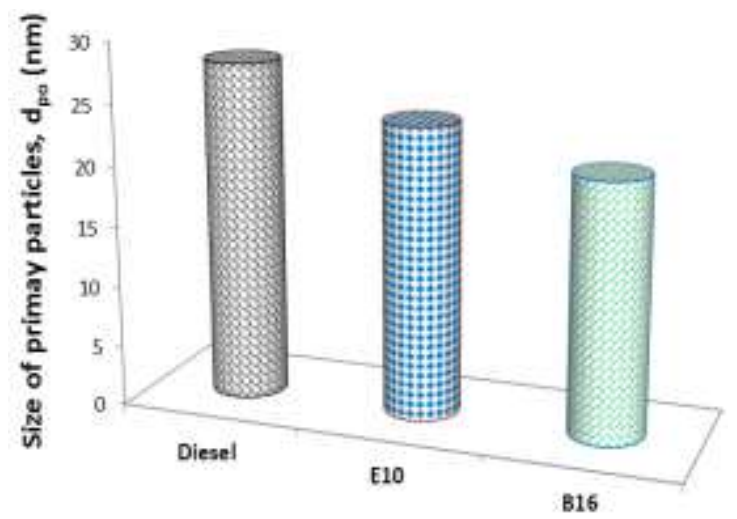

Figure 7: Average size of soot primary particles for diesel fuel, E10 and B16 blends

\section{Conclusions}

The effect of oxygenated fuels (B16 and E10) on morphological characteristics of particulate soot matter (PM) was studied. It noticed that the PM agglomerates from the oxygenated fuel's combustion have a lower number of primary particles than those formed from the diesel fuel combustion. This work shows that oxygenated fuels enhance soot particle oxidation at lower temperatures and short time compared to diesel fuel; therefore, this will improve the lower temperature in engine exhaust and catalyst activity. Furthermore, it can be concluded from the current results that oxygen content in E10 and B16 has a positive aspect in enhancing the soot oxidation rate and inhibit the rate of soot formation, resulting in soot particles, being less effect on diesel particulate filter and environment. Moreover, the diameter size of the primary particulate is more spherical from the diesel fuel combustion than to the oxygenated fuels due to the higher value of PM size.

Comparing the same oxygen content $(5 \mathrm{wt} \%)$ for two oxygenated fuel, B16 has slightly effective in reduction size and nanostructure parameters of soot particulate than E10 blend. The chemical properties and efficient oxygen content from B16 fuel used in this experimental study lead to providing beneficial effective on soot particle reduction (size and number) and oxidation (lower activation energy) than E10. In general, the positive results from oxygenated fuels will positively influence the combustion process and after treatment, systems (increase the lifetime).

\author{
Abbreviations \\ B 16: Butanol 16\%, RME 15\%, and diesel $69 \%$ \\ E10: Ethanol 10\%, RME 15\%, and diesel $75 \%$ \\ IMEP: Indicated mean effective pressure \\ $n_{p o}$-Number of primary particles \\ $\mathrm{R}_{\mathrm{g}}$ : Radius of gyration \\ RME: Rapeseed oil methyl ester \\ SMPS: Scanning mobility particle sizer \\ PM: Particulatematter \\ SMPS: Scanning mobility particle sizer \\ TGA: Thermal gravimetric analysis
}

\section{References}

[1] H. Burtscher, "Physical characterization of particulate emissions from diesel engines: A review," Journal of Aerosol Science, 36, p. 896-932, 2015.

$[\ulcorner]$ Y.F. Xing, Y.H. Xu, M.H. Shi, Y.X. Lian, "The impact of PM2. 5 on the human respiratory system," Journal of thoracic disease, 8, 1, p. E69, 2016.

[־] M.A. Fayad, A. Tsolakis, D. Fernández-Rodríguez, J.M. Herreros, F.J. Martos, M. Lapuerta, "Manipulating modern diesel engine particulate emission characteristics through butanol fuel blending and fuel injection strategies for efficient diesel oxidation catalysts," Appl. Energ., 190, p. 490-500, 2017.

[£] S.S. Gill, G.S. Chatha, A. Tsolakis, "Analysis of reformed EGR on the performance of a diesel particulate filter," Int. J. Hydrogen Energy, 36, 16, p. 10089-10099, 2011.

[0] B.S. Haynes, H.G.G. Wagner, "Soot formation", Prog. Energy Combust SCI, 7, p. 229-73, 1981.

[^] C.D. Rakopoulos, D.T. Hountalas, T.C. Zannis, "Operational and environmental evaluation of diesel engines burning oxygen-enriched intake air or oxygenenriched fuels: a review," SAE Technical Paper, p. 012924, 2004.

[₹] H.L. Fang, and M.J. Lance, "Influence of Soot Surface Changes on DPF Regeneration. SAE Technical Paper, p. 01-3043, 2004.

[^] D. Fino, S. Bensaid, M. Piumetti, N. Russo, "A review on the catalytic combustion of soot in diesel particulate filters for automotive applications: from powder catalysts to structured reactors," Applied Catalysis A: General, 509: p. 75-96, 2016.

[9] K.O. Lee, R. Cole, R. Sekar, M.Y. Choi, J. Kang, C. Bae, "Detailed characterization of morphology and dimensions of diesel particulates via thermophoretic sampling," SAE Technical Paper, 2001.

['·] J. Zhu, K. Lee, A. Panov, J. Akers, C. Habeger, "An investigation of particulate morphology, microstructures, and fractal geometry for a diesel engine-simulating combustor," SAE transactions, p. 2062-2069, 2004.

[' '] K. Al-Qurashi, A.L. Boehman, "Impact of exhaust gas recirculation (EGR) on the oxidative reactivity of diesel engine soot," Combustion and Flame, 155, p. 675695, 2008. 
[Y $]$ J. Song, M. Alam, A.L. Boehman, U. Kim, "Examination of the oxidation behaviour of biodiesel soot," Combustion and Flame, 146, p. 589-604, 2006.

[I $\left.{ }^{\mathrm{T}}\right]$ A. Setiabudi, M. Makkee, J.A. Moulijn, "The role of $\mathrm{NO}_{2}$ and $\mathrm{O}_{2}$ in the accelerated combustion of soot in diesel exhaust gases," Applied Catalysis B: Environmental, 50, 3, p. 185-194, 2004.

[ \ ₹] J.O. Müller, D.S. Su, R.E. Jenthoft, J. Kröhnert, R. Schlögl, "Morphology-controlled reactivity of carbonaceous materials towards oxidation," Catalyst Today, 102-103, p. 259-265, 2005.

[10] S.H. Kim, R.A. Fletcher, M.R. Zachariah, "Understanding the difference in oxidative properties between flame and diesel soot nanoparticles: The role of metals," Environmental science \& technology, 39, 11, p. 4021-4026, 2005.

[17]A. Yezerets, N.W. Currier, H.A. Eadler, "Experimental determination of the kinetics of diesel soot oxidation by $\mathrm{O}_{2}$-modeling consequences," SAE Technical Paper, 2003.

[I v] T. Ishiguro, N. Suzuki, Y. Fujitani, H. Morimoto, "Microstructural Changes of Diesel Soot during Oxidation, Combustion and Flame, 85, 1-2, p. 1-6, 1991.

[`^] E. Sukjit, J.M. Herreros, K.D. Dearn, R. GarciaContreras, A. Tsolakis, "The effect of the addition of individual methyl esters on the combustion and emissions of ethanol and butanol -diesel blends," Energy, 42, 1, p. 364-374, 2012.

[19] E. Sukjit, J.M. Herreros, J. Piaszyk, K.D. Dearn, A. Tsolakis, "Finding synergies in fuels properties for the design of renewable fuels-Hydroxylated biodiesel effects on butanol-diesel blends," Environ. Sci. Tech., 47, 7, p. 3535-3542, 2013.

$\left[{ }^{r} \cdot\right]$ M.A. Fayad, "Effect of renewable fuel and injection strategies on combustion characteristics and gaseous emissions in diesel engines. Energy Sources, Part A: Recovery," Utilization, and Environmental Effects, p. 1-11, 2019.

[Y ] D.C. Rakopoulos, C.D. Rakopoulos, E.G. Giakoumis, A.M. Dimaratos, D.C. Kyritsis, "Effects of butanol-diesel fuel blends on the performance and emissions of a highspeed DI diesel engine," Energy Conversion and Management, 51, p. 1989-1997, 2010.

$\left[{ }^{r}\right]$ C.D. Rakopoulos, A.M. Dimaratos, E.G. Giakoumis, D.C. \& Rakopoulos, "Investigating the emissions during acceleration of a turbocharged diesel engine operating with bio-diesel or n-butanol diesel fuel blends," Energy 35, 12, p. 5173-84, 2010.

$\left[{ }^{r}\right]$ M.A. Fayad, D. Fernández-Rodríguez, J.M. Herreros, M. Lapuerta, A. Tsolakis, "Interactions between aftertreatment systems architecture and combustion of oxygenated fuels for improved low temperature catalysts activity," Fuel, 229, p. 189-197, 2018.

[r $\varepsilon]$ P. Pepiot-Desjardins, H. Pistch, R. Malhotra, S.R. Kirby, A.L. Boehman, "Structural group analysis for soot reduction tendency of oxygenated fuels," Combustion and Flame, 154, p. 191-205, 2008

[ro] W.J. Lee, F.K. Wangi, W.H. Chen, S.L. Lin, Y. Fukushima, et al., "Assessment of energy performance and air pollutant emissions in a diesel engine generator fueled with water-containing ethanol-biodiesel-diesel blend of fuels," Energy, 36, 9, p. 5591-9, 2011.

[Yฯ]Z. Zhang, R. Balasubramanian, "Effects of oxygenated fuel blends on carbonaceous particulate composition and particle size distributions from a stationary diesel engine," Fuel, 141, p. 1-8, 2015.

[rv] M.A. Fayad, J.M. Herreros, F.J. Martos, A. Tsolakis, "Role of Alternative Fuels on Particulate Matter (PM) Characteristics and Influence of the Diesel Oxidation Catalyst," Environ. Sci. Tech., 49, 19, p. 11967-11973, 2015.

[Y^] H. An, W. Yang, J. Li, D. Zhou, "Modeling study of oxygenated fuels on diesel combustion: Effects of oxygen concentration, cetane number and $\mathrm{C} / \mathrm{H}$ ratio," Energy Conversion and Management, 90, p. 261-271, 2015.

[ץ৭] C.J. Mueller, W.J. Pitz, L.M. Pickett, G.C. Martin, D.L. Siebers, C.K. Westbrook, "Effects of oxygenates on soot processes in DI diesel engines: Experiments and numerical simulations," SAE Technical Paper, p. 01-1791, 2003.

$[r \cdot]$ C.E. Dumitrescu, C.J. Mueller, E. Kurtz, "Investigation of a tripropylene-glycol monomethyl ether and diesel blend for soot-free combustion in an optical direct-injection diesel engine," Applied Thermal Engineering, 101, p. 639-646, 2016.

[YI] C.K. Westbrook, W.J. Pitz, and H.J. Curran, "Chemical kinetic modeling study of the effects of oxygenated hydrocarbons on soot emissions from diesel engines,” J. Phys. Chem. A, 110, 21, p. 6912-6922, 2006.

$\left[{ }^{r}\right.$ Y $]$ S.S. Gill, A. Tsolakis, J.M. Herreros, A.P.E. York, "Diesel emissions improvements through the use of biodiesel or oxygenated blending components," Fuel, 95, p. 578-586, 2011.

$\left[{ }^{\top}\right]$ E.J. Barrientos, "Impact of Oxygenated Fuels on Sooting Tendency and Soot Oxidative Reactivity with Application to Biofuels," [Ph.D. thesis]. 2014.

[r飞] M. Lapuerta, M. Herreros, J.M. Lyons, L. Lisbeth, García-Contreras, Reyes, Briceño, Yolanda, "Effect of the alcohol type used in the production of waste cooking oil biodiesel on diesel performance and emissions," Fuel, 87, 15, p. 3161-3169, 2008

[ro] M. Lapuerta, F. Oliva, J.R. Agudelo, A.L. Boehman, "Effect of fuel on the soot nanostructure and consequences on loading and regeneration of diesel particulate filters," Combustion and Flame, 159, 2, p. 844-853, 2012.

[Y ] O.P. Bhardwaj, B. Lüers, B. Holderbaum, T. Koerfer, $\mathrm{S}$. Pischinger and M. Honkanen, "Utilization of HVO fuel properties in a high efficiency combustion system: Part 2: Relationship of soot characteristics with its oxidation behavior in DPF," SAE International Journal of Fuels and Lubricants, 7, 2014-01-2846, p. 979-994, 2014.

$[r \vee]$ K.K. Park, P.H. McMurry, "Structural properties of diesel exhaust particles measured by transmission electron microscopy (TEM): Relationships to particle mass and mobility," Aerosol Science and Technology, 38, 9, p. 881889, 2004.

[r^] J.J. Hwang, C. Bae, "Particulate morphology of waste cooking oil biodiesel and diesel in a heavy duty diesel 
engine," in International Conference on Optical Particle Characterization (OPC 2014), International Society for Optics and Photonics, 2014.

[rq] L. Qu, Z. Wang, H. Hu, X. Li, Y. Zhao, "Effects of butanol on components and morphology of particles emitted by diesel engines," Research of Environmental Sciences, 28, 10, p. 1518-1523, 2015. 